Dr Backer is a consultant for W. L. Gore \& Associates, Inc.

The Journal policy requires editors and reviewers to disclose conflicts of interest and to decline handling or reviewing manuscripts for which they may have a conflict of interest. The editors and reviewers of this article have no conflicts of interest.

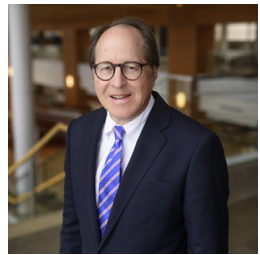

\section{REPLY: EMBRACING REGIONALIZATION WORLDWIDE}

\section{Reply to the Editor:}

I greatly appreciate the comments of Dr Vervoort, ${ }^{1}$ who in his letter to the editor encourages us to focus on the regionalization of congenital heart surgery on a global level. His summary statement that the question of regionalization is often one of revenue, pride, and/or politics is extremely accurate and telling.

Dr Vervoort points out that with the advent of new cardiac surgical centers in low- and middle-income countries, we must encourage them not to repeat the same mistakes that have already occurred in many high-income countries.

Governments developing new centers need to focus on fewer centers with greater volume per center to improve outcomes while simultaneously promoting efficiency, reducing health system costs, and ensuring specialized health workers across all layers of care.

This is exactly what was done in Sweden, and these changes should be recommended for existing health care systems not only in the United States but also for new pediatric cardiac surgical centers in developing countries.

There is increasing evidence that greater-volume centers properly located can both improve outcomes and actually decrease travel distance for those needing care. Those of us who live in high-income countries have learned this lesson the hard way and this error should not be repeated in low- and middle-income countries. Regionalization of care for children with congenital heart disease is now a truly global issue, and responsibility for its inception rests with our profession.

Carl L. Backer, MD Section of Pediatric Cardiothoracic Surgery UK HealthCare Kentucky Children's Hospital Lexington, Ky Cardiothoracic Surgery Heart Institute Cincinnati Children's Hospital Medical Center Cincinnati, Ohio

\section{Reference}

1. Vervoort D. Centralization and regionalization of congenital heart surgery in a globalized world. J Thorac Cardiovasc Surg. 2021;161:e481.

https://doi.org/10.1016/j.jtcvs.2020.09.095

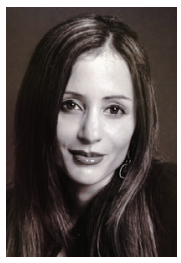

\section{REPLY: TRUTH OR \\ DARE-GLOBAL REGIONALIZATION OF CONGENITAL HEART CARE}

Reply to the Editor:

I have always preferred the "dare" option, but I think in this particular game, where there are really no winners, I'm going with "truth." Your turn...

Dare: In a response to the editor in this issue of the Jour$n a l,{ }^{1}$ Vervoort expands our argument ${ }^{2}$ for regionalization of congenital cardiac surgery services beyond the borders of the continental United States. Vervoort argues that proliferation of centers within low- to middle-income countries (LMICs), a phenomenon he refers to as 'fragmentation,' will adversely impact quality and more importantly, fail to achieve the goal of increasing surgical coverage for $80 \%$ of the pediatric population with congenital heart disease (CHD). While I agree with the concept that the development of optimized cardiac surgery care delivery in LMICs should be based on a centralized structure, the success of this initiative depends on strategic alignment of domestic and foreign financial investments, training program establishment and expansion, and implementation of comprehensive mechanisms for data collection. Martin ${ }^{3}$ articulated the need to address these issues in his commentary to the American College of Cardiology in 2016, pointing out that only $7 \%$ of the population in developing countries has access to pediatric cardiac surgery and only $20 \%$ of the current pediatric cardiac surgery workforce practice in LMICs.

Concentrated efforts to build scalable, high-quality congenital cardiac surgical care within LMICs mandates initial investment in centralized training facilities that adapt empirically-derived best practices to local environments. Global quality-based registries with streamlined required data elements should be simultaneously employed to provide fundamental benchmarks for operative mortality and monitor the establishment of surveillance programs to record longer-term outcomes. The latter cannot be overemphasized, as follow-up for patients with CHD is paramount to reduce unnecessary acuity-based expenditures and limit overall population-based resource use. Coupling domestic investment with the considerable developmental aid from organizations such as Children's HeartLink will be required to offset the costs of these critical formative steps. 